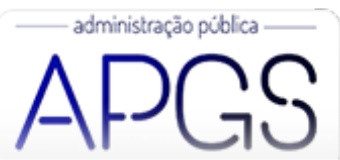

Administração Pública e Gestão Social ISSN: 2175-5787

apgs@ufv.br

Universidade Federal de Viçosa

Brasil

\title{
Descentralização na gestão das águas: um processo ainda em construção?
}

Nunes, Elizabet; Fadul, Élvia; Santos Cerqueira, Lucas

Descentralização na gestão das águas: um processo ainda em construção?

Administração Pública e Gestão Social, vol. 11, núm. 3, 2019

Universidade Federal de Viçosa, Brasil

Disponível em: http://www.redalyc.org/articulo.oa?id=351559268002

Esta obra está bajo una Licencia Creative Commons Atribución-NoComercial-SinDerivar 3.0 Internacional 


\section{Descentralização na gestão das águas: um processo ainda em construção?}

Decentralization in water management: a process still under construction?

La descentralización en la gestión del agua: ęun proceso aún em construcción?

Elizabet Nunes

Universidade Salvador, Brasil

elizabetenunes80@hotmail.com

Élvia Fadul

Universidade Salvador, Brasil

elvia@unifacs.br

Lucas Santos Cerqueira

Universidade Federal do Rio Grande, Brasil

lucasscerqueira@gmail.com
Redalyc: http://www.redalyc.org/articulo.oa? $\mathrm{id}=351559268002$
Recepção: 19 Agosto 2016

Aprovação: 09 Março 2019

Publicado: 01 Julho 2019

\section{Resumo:}

Este trabalho discute os fatores propulsores e restritivos que têm influenciado a viabilidade do modelo de gestão de recursos hídricos aplicada ao comitê de bacia do Recôncavo Norte e Inhambupe, no Estado da Bahia, à luz da descentralização. Este é um estudo exploratório-descritivo realizado mediante observação direta, aplicação de questionários e entrevistas e análise qualitativa. A pesquisa demonstrou que a descentralização favorece a tomada de decisão, a democracia, as condições de governabilidade e governança do comitê. Contudo, a inexistência do plano de bacia, da agência de água e da cobrança pelo uso da água fazem com que o comitê ainda tenha pouca autonomia e poder decisório para efetivar a descentralização.

Palavras-chave: Gestão de Recursos Hídricos, Comitês de Bacias Hidrográficas, Descentralização.

\section{Abstract:}

This article discusses the proppeling and restrictive factors that have influenced the viability of water resources management model, applied to the Recôncavo Norte and Inhambupe basin committee in the State of Bahia, Brazil, in the light of decentralization. This exploratory-descriptive study was conducted through direct observation, questionnaires and interviews, and qualitative analysis. Research has shown that decentralization promotes decision-making, democracy, governability and governance conditions in the committee. However, the lack of a basin plan, a water agency and a water use charge means that the committee still has little autonomy and decision-making power to effect decentralization.

KEYWORDS: Management of Water Resources, River Basin Committees, Decentralization.

\section{Resumen:}

Este trabajo discute los factores propulsores y restrictivos que han influenciado la viabilidad del modelo de gestión de recursos hídricos, aplicada al Comité de Cuenca del Recôncavo Norte e Inhambupe, en el Estado de Bahía, en Brasil, a la luz de la descentralización. Este es un estudio exploratorio-descriptivo realizado mediante observación directa, aplicación de cuestionarios y entrevistas, y análisis cualitativo. La investigación demostró que la descentralización favorece la toma de decisiones, la democracia, las condiciones de gobernabilidad y gobernanza del comité. Con todo, la inexistencia del plan de cuenca, de la agencia de agua y del cobro por el uso del agua hacen que el comité tenga poca autonomía y poder decisorio para efectivizar la descentralización.

Palabras clave: Gestión de los Recursos Hídricos, Comités de Cuencas Hidrográficas, Descentralización. 


\section{INTRODUÇÃO}

O tema da descentralização, a partir de meados da década de 1980, tem se revelado presente nas discussões políticas e acadêmicas, ampliando a quantidade de trabalhos publicados, tanto aqueles que tratam o termo conceitualmente, quanto os que trazem experiências desse processo, no Brasil e em outros países. Para Guimarães (2014), por exemplo, o tema “transformou-se numa espécie de bandeira universal”, sendo discutido em vários campos disciplinares, como a Ciência Política, as Ciências Econômicas, a Sociologia e a Administração Pública.

No campo da Administração Pública, no Brasil, apesar de já em 1967 o Decreto-Lei no 200/67 (Brasil, 1967) ter trazido indícios das reformas gerenciais que ocorreriam em países como Estados Unidos e Inglaterra a partir dos anos 1980, definindo, em seu art. 6º inciso III, a descentralização como um dos seus princípios básicos, somente após a promulgação da Constituição de 1988 (Brasil, 1988) é que os estados e municípios brasileiros tornaram-se, de fato, politicamente autônomos e as bases do Estado federativo do Brasil foram recuperadas. Pode-se dizer, então, que essa Constituição exerceu sua função também como legitimadora do mecanismo da descentralização, através do estabelecimento de um novo arranjo federativo e da transferência de decisões, funções e recursos do nível federal para os estados e municípios.

A descentralização ocorre quando o Estado desempenha algumas de suas atribuições por meio de outras entidades e não pela sua administração direta. Pressupõe duas pessoas distintas: o Estado, na figura da União, ou do Distrito Federal, ou de um estado ou de um município, e a entidade que executará o serviço, por ter recebido do Estado essa atribuição através de outorga ou delegação. Em termos objetivos e simples, "Descentralizar significa repartir e delegar competências, impondo atribuições para níveis hierárquicos inferiores, (...)" (Ferreira \& Ferreira, 2006, p.9).

Os processos de descentralização ocorreram no país em diversos setores, notadamente nos setores sociais como saúde e educação. No entanto, um exemplo em serviços de infraestrutura que tem se destacado mais recentemente nos debates acadêmicos é a gestão de recursos hídricos por comitês de bacias hidrográficas.

Com a Lei no 9.433/97 (Brasil, 1997), também conhecida como Lei das Águas, a bacia hidrográfica passa a ser a unidade para a implementação da Política Nacional de Recursos Hídricos. Um dos princípios básicos para a gestão dos recursos hídricos instituído por esta lei é que o gerenciamento dos recursos hídricos deve ser descentralizado e envolver a participação do governo, dos usuários e das comunidades locais. Isso significa, em poucas palavras, que decisões sobre o uso dos recursos hídricos saem do âmbito do governo federalou do Ministério de Meio Ambiente e Recursos Hídricos e descem ou descentralizam-se para a comunidade local envolvida geográfica, social e economicamente com determinada bacia hidrográfica. Ou seja, os comitês assumem competência em questões relacionadas a arbitrar conflitos relacionados às águas, aprovar e acompanhar a execução do Plano de Recursos Hídricos da bacia, estabelecer os mecanismos de cobrança pelo uso de recursos hídricos e critérios para promover o rateio do custo das obras de uso múltiplo, de interesse comum ou coletivo.

Há argumentos favoráveis e desfavoráveis à descentralização, inclusive quando esta se associa ao envolvimento de outros atores no processo decisório. Do mesmo modo, pesquisas apontam aspectos potencializadores e dificultadores da descentralização em alguns setores. É justamente nessa discussão que este artigo pretende avançar, utilizando o processo de institucionalização da gestão de recursos hídricos por comitês de bacias hidrográficas como objeto de estudo, procurando analisar a sua efetividade no funcionamento desse modelo de gestão nesse setor.

Consideram-se também como argumentos que subsidiam o estudo e justificam a pesquisa, a crise ambiental que se assevera (Santos, 2002; Cerqueira, 2017), em decorrência do modelo de exploração capitalista que pressupõe o uso irracional e indiscriminado da natureza (Mészaros, 2002), afetando a gestão das águas em todo o país, a crise na regulação do Estado (Rio, Moura \& Sales, 2004), cujo desafio de assegurar um sistema descentralizado e participativo frente ao avanço das políticas neoliberais (Dagnino, 2004) se mostra 
emergente. Destaca-se, ainda, o exemplo da transposição do Rio São Francisco, em que foi desrespeitada a decisão do comitê, contrária ao projeto, e o estado de agonia em que se encontra o rio com as secas, degradação e poluição (Spínola,Vitoria \& Cerqueira, 2016), que afeta diretamente a população e não garante a oferta das águas para as gerações futuras, como presume a Lei das Águas.

Para atingir seu objetivo, o presente artigo, após esta introdução, apresenta um breve histórico da gestão das águas no Brasil, procurando mostrar a tradição centralizadora que imperava no país, nesse setor. Em seguida, trava uma discussão, a partir de alguns autores, sobre os conceitos e aplicações da descentralização, seus aspectos favoráveis e desfavoráveis. Indica, a seguir, os procedimentos metodológicos, para, por fim, destacar os aspectos da descentralização que interferem na gestão das águas, trazendo, no final, as conclusões.

\section{Da CEnTRALIZAÇÃo AOS COMITÊS DE BACIAS HIDROgRÁFICAS: O LONGO CAMINHO DA GESTÃo DAS ÁGUAS No BrasiL}

De acordo com o Plano Nacional de Recursos Hídricos (PNRH), a história da preocupação com o uso sustentável e racional da água no Brasil, considerando suas várias possibilidades de fruição humana, não é muito longa, mesmo considerando o pouco mais de quinhentos anos de conhecimento das atividades que se desenrolaram progressivamente no território de nosso país a partir do descobrimento (PNRH, 2006). Nas principais atividades econômicas do período colonial, a saber, a agricultura e a mineração, embora apresentasse grande potencial de desenvolvimento, não houve relatos de grandes conflitos de uso da água, e estes se limitavam a questões de vizinhança e de empecilhos à navegação.

Contudo, a industrialização e a expansão de alguns núcleos populacionais, antigos ou emergentes, em crescimento acelerado a partir do último terço do século XIX, rapidamente passam a aumentar a demanda de água, a exigir maior regularidade no seu fornecimento e a construção de instrumentos legais mais complexos para seu gerenciamento. Mas foi somente com o advento da República e com o início da sofisticação da Administração Pública que a sociedade brasileira iniciou seus primeiros passos para a conformação de um aparato legal e institucional destinado ao controle sobre o uso dos seus recursos naturais, entre os quais a água. (PNRH, 2006).

Vale salientar que, até meados do século XIX, o fornecimento de água e saneamento no país era bastante precário, o que contribuía para que epidemias se alastrassem na população. Só a partir de então é que os conselhos municipais e o governo passaram a ser responsáveis pelo abastecimento de água e pelo saneamento. Porém, devido à debilidade tecnológica que o Brasil apresentava naquela época, foi necessária a contratação de empresas estrangeiras para prestação desses serviços. (Barraqué, Formiga-Johnsson \& Nogueira, 2008).

Nesse período, somente as cidades do Rio de Janeiro e São Paulo possuíam serviços de água e de saneamento, devido a um convênio entre o governo brasileiro e organizações inglesas. No entanto, somente edifícios públicos e religiosos e bairros abastados foram contemplados pelos serviços que até então eram gratuitos (Barraqué, Formiga-Johnsson \& Nogueira, 2008).

Desde o início do século passado, a Legislação Brasileira traz, de forma tímida, a questão das águas, inicialmente em 1934, através do Decreto $\mathrm{n}^{\circ}$ 24.643/34, o Código das Águas, que está dividido em três volumes: Águas em Geral e sua Propriedade, Aproveitamento das Águas e Forças Hidráulicas e Regulamentação da Indústria Hidroelétrica.

Segundo Borsoi \& Torres (1997), a primeira fase tinha como principal objetivo cumprir e fazer cumprir os dispositivos legais sobre águas através de uma gestão fragmentada, com centralização do poder decisório, excesso de formalismo, entre outros. Desta forma, o modelo de gestão de recursos hídricos mostrou-se ineficiente em resolver os problemas relativos ao uso e à proteção das águas, como também a criação de instrumentos legais à resolução dos mesmos. 
A segunda etapa foi marcada pela priorização de programas setoriais do governo, principalmente os que eram voltados para a irrigação e produção energética, por vezes em detrimento do saneamento e do abastecimento, como afirmam Barraqué, Formiga-Johnsson \& Nogueira (2008):

As primeiras transferências de água importantes no Brasil foram para produzir energia elétrica para a região metropolitana de São Paulo e Rio de Janeiro, mas depois entrou em conflito com o abastecimento de água urbano. (Barraqué, FormigaJohnsson \& Nogueira, 2008, p.7).

A primeira experiência brasileira na gestão de recursos hídricos estava vinculada à questão agrícola e teve início na década de 1930, através do Ministério da Agricultura. Em 1934, esse serviço foi transferido para a estrutura do Departamento Nacional de Pesquisa Mineral (DNPM), e, na sequência, ocorreu a edição do Código de Águas, estabelecido pelo Decreto ${ }^{\circ}{ }^{24.643}$, de 10/07/34. Esse código, como outros instrumentos legais que disciplinam as atividades do setor, provém de um modelo de gerenciamento de águas orientado por tipos de uso (Borsoi \& Torres, 1997).

Nesse período era o Governo Federal quem legislava sobre os recursos hídricos e a concessão do potencial hidráulico e, por fim, tornou-se necessária a concessão ou autorização administrativa através da definição de domínios, inclusive particulares, como também a introdução do sistema poluidor-pagador com penalidades para os infratores.

Enfim, como resultado das políticas desenvolvimentistas da época, o crescimento do país resultou em centros urbanos desordenados. A industrialização, a agricultura e a mineração, bastante ativas, por outro lado, trouxeram também a degradação dos corpos d'água e escassez do fornecimento. O Código das Águas, no entanto, não previa isso, nem foi alterado por alguma proposta de plano de ação. Para tentar suprir essa crescente demanda, o governo passou a construir obras de grande porte, já adotando o modelo econômicofinanceiro de gestão, conhecido como uso múltiplo. Como exemplo tem-se a Companhia do Vale do São Francisco (CODEVASF), (Pereira, 2008).

Em 1988, a Constituição Federal promulgada trouxe vários dispositivos sobre a gestão das águas no país, a exemplo do artigo 21, inciso XIX, que traz: "Compete à União instituir o Sistema Nacional de Gerenciamento de Recursos Hídricos e definir critérios de outorga de direito de uso" (Brasil, 1988), transformando a água em domínio público e introduzindo a noção de bacia hidrográfica como unidade de planejamento.

É somente no final da década de 1990 que a essa tradição centralizadora é rompida, ainda que, inicialmente, apenas de forma legal, pela promulgação da Lei no 9433/97 (Brasil, 1997), dando nova versão à gestão de recursos hídricos no país. Essa lei foi encaminhada pelo Governo Federal ao Congresso Nacional em 1991, com o projeto que tratava da Política Nacional de Recursos Hídricos e a proposta para a criação do Sistema Nacional de Gerenciamento de Recursos Hídricos, e levou seis anos tramitando no congresso, sendo aprovada e sancionada em janeiro de 1997.

\section{A descentralizaÇÃo e a gestão das Águas}

O termo descentralização encerra alguns conceitos. Pensar na significação do termo, no entanto, implica, em primeiro lugar, pensar em organização e, de certa forma, em hierarquização, mas sem subordinação. Em seguida, o termo encerra também a ideia de poder e de repartição desse poder em diversos níveis ou entre diversos atores. A ideia de descentralização repousa, portanto, no fato de que competências, responsabilidades e, consequentemente, poder, são repartidos entre um comando central e uma instância periférica. A descentralização ocorre quando o Estado desempenha algumas de suas atribuições por meio de outras entidades, e não pela sua administração direta. Falar em descentralização envolve, também, questões que extrapolam o significado do conceito do ponto de vista da administração, e ganham espaço nas análises políticas, tais como autonomia local, democracia participativa, racionalização da provisão de serviços, maior 
liberdade, maior responsabilidade e maior autonomia de decisão dos gestores públicos (Arretche, 1996; Guimarães, 2002; Abrúcio, 2006, Di Pietro, 2010).

No caso da descentralização no Estado brasileiro, a União continua a ser o núcleo central do Estado na esfera federal, havendo uma repartição de poderes com outras unidades autônomas, os estados e os municípios, que possuem, em certa medida, independência, autonomia política, organizacional e, principalmente, financeira.

No entanto, a descentralização também tem sido um termo utilizado para denominar a transferência de atribuições do Estado para a iniciativa privada, através da privatização ou da concessão de serviços públicos e a transferência de poder do governo para uma comunidade ou uma organização social, o que diverge da concepção de Abrúcio (2006), para quem a descentralização é:

Um processo nitidamente político, circunscrito a um Estado nacional, que resulta da transferência (ou conquista) efetiva de poder decisório a governos subnacionais, que: a) adquirem autonomia para escolher seus governantes e legisladores, b) para comandar diretamente sua administração, c) para elaborar uma legislação referente às competências que lhes cabem, e, por fim, d) para cuidar de sua estrutura tributária e financeira. (Abrúcio, 2006, p. 78).

Na perspectiva democrática da descentralização, Arretche(1996) afirma que:

Passou-se a supor que, por definição, formas descentralizadas de prestação de serviços públicos seriam mais democráticas e que, além disso, fortaleceriam e consolidariam a democracia. [...] Portanto, reformas do Estado nessa direção seriam desejáveis, dado que viabilizariam a concretização de ideais progressistas, tais como equidade, justiça social, redução do clientelismo e aumento do controle social sobre o Estado. (Arretche, 1996, p. 1).

Guimarães (2002) caracteriza a descentralização dentro do plano político e instituicional em três dimensões: administrativa, social e política. Na dimensão administrativa, a descentralização está relacionada à delegação, à transferência de competências e de funções entre unidades, níveis de governo ou até mesmo entre órgãos. Na dimensão social, busca a promoção da participação social na gestão pública, passando parte do poder decisório à sociedade civil. Na dimensão política, a descentralização aparece como uma estratégia para a redistribuição do poder político do Estado do nível central para os demais.

Abrúcio (2002), entretanto, discorda desta tipologia apresentada por Guimarães (2002), explicando que a delegação de funções de órgãos centrais para agências mais autônomas é, na verdade, um processo de desconcentração administrativa, ou ainda, a horizontalização das estruturas organizacionais públicas através de repasse de maior responsabilidade da cúpula aos gerentes e demais funcionários. Continua dizendo que a descentralização também é confundida com a privatização ou concessão de serviços públicos quando é utilizada para denominar a transferência de atribuições do Estado à iniciativa privada, à sociedade civil ou às ONGs. "Estes três processos não podem ser simplesmente equiparados à descentralização no seu sentido estrito, embora possam conviver com ela ou mesmo serem impulsionados por mudanças políticas descentralizadoras." (Abrúcio, 2002, p. 146).

Souza (1997), por exemplo, traz alguns argumentos de caráter hegemônico que considera favoráveis à descentralização, quais sejam: a possibilidade de realizar profundas mudanças nas estruturas estatais, tais como reformas de cunho fiscal, econômico, financeiro-administrativo, além da reordenação territorial; a ampliação da autonomia dos municípios em relação aos serviços públicos descentralizados; a gestão global, integral e não setorial das políticas no âmbito territorial, mantendo o Estado central como a principal fonte de recursos; a possibilidade de unidades locais interferirem nos processos de formulação das políticas, criando instituições representativas locais; novas formas de articulação entre os setores público e privado, com maior integração entre Estado e sociedade civil no plano local; estímulo a novas práticas participativas; combinação de mecanismos de representação tradicionais (partidos, sindicatos) com novas formas institucionalizadas de gestão de serviços e de políticas descentralizadas (conselhos, comissões). 
Borja (1988) destaca a importância da descentralização como forma de diminuir, ao mesmo tempo, as discrepâncias sociais e o dualismo decorrentes da adoção de políticas excludentes, verificados ao longo da existência do antigo modelo e que cresceriam diante do neoliberalismo (Borja 1988, apud Souza, 1997, p.18).

Em contrapartida, Abrúcio (2002) aponta cinco aspectos negativos que podem ocorrer em um processo de descentralização:

(...) a constituição de um sólido pacto nacional, o ataque às desigualdades regionais, a criação de um ambiente contrário à competição predatória entre os entes governamentais, a montagem de boas estruturas administrativas no plano subnacional e a democratização dos governos locais. (Abrúcio, 2002, p. 153)

Constituição de um sólido pacto nacional: “(...) refere-se à relação dos governos locais com a nação, visto que uma descentralização excessiva pode ocasionar uma guerra civil, uma secessão ou a desordem econômica” (Abrúcio, 2002, p. 153).

Ataque às desigualdades regionais: “(...) é preciso evitar o crescimento das desigualdades regionais através de políticas redistributivas ou compensatórias” (Abrúcio, 2002, p. 154).

Criação de um ambiente contrário à competição predatória entre os entes governamentais: ocorre quando os governos centrais não conseguem lidar com a nova realidade e procuram evitar a perda de autoridade e competências ou quando a ausência de experiência em autogoverno e o enfraquecimento do poder nacional podem estimular a irresponsabilidade fiscal nas unidades subnacionais. Em ambos os casos há fragilidade de instrumentos de cooperação e coordenação entre as esferas de poder (Abrúcio, 2002, p. 154).

Montagem de boas estruturas administrativas no plano subnacional: falta de desenvolvimento de “(...) capacidades administrativas e financeiras dos entes subnacionais que ajudem a melhorar o desempenho da gestão pública" (Abrúcio, 2002, p. 155).

Democratização dos governos locais: não compreensão de que "A relação descentralização e democracia não é linear” (Abrúcio, 2002, p. 155). Ela depende da construção político-institucional de cada lugar.

Trazendo o conceito de descentralização para a gestão de recursos hídricos, Pereira e Formiga-Johnsson (2005) destacam que:

Descentralização na política de recursos hídricos significa a institucionalização, em nível local, de condições institucionais, técnicas, financeiras e organizacionais para a implementação das tarefas de gestão, conforme atribuições designadas na lei de recursos hídricos, garantindo continuidade no fluxo da oferta dos bens e serviços. (Pereira \& Formiga-Johnson, 2005, p. 3).

Machado (2003), por sua vez, acrescenta que a descentralização da gestão das águas possui alguns objetivos: assegurar a diversidade de interesses de cada segmento nas decisões tomadas, favorecer uma maior fiscalização e controle por parte dos cidadãos com relação às ações realizadas pelo Comitê e, finalmente, produzir e disponibilizar para a sociedade informações sobre o comitê e sobre os recursos hídricos geridos. Esses comitês, que foram criados para defender os interesses da coletividade, o fazem através da participação em um sistema de cogestão que permite a articulação, a discussão e a negociação, com base em princípios sócio-técnicos que permitem a participação de todos os interessados. Para o autor, o processo decisório descentralizado é importante na medida em que esse formato pode diminuir o risco de corrupção e de atendimento de interesses privados em detrimento do interesse público, limitando a arbitrariedade tanto no que se refere à tomada de decisão individual como por parte do poder público. Conclui dizendo ainda que "O comitê, portanto, previne e reduz riscos de que o aparato público seja apropriado por interesses imediatistas, orientando as políticas públicas e formulando planos de desenvolvimento integrado." (Machado, 2003, p.127).

Já Abers \& Keck (2004) apresentam esse modelo de gestão apoiado em dois argumentos: o primeiro defende que a gestão descentralizada e participativa gera uma maior democracia e o segundo, que favorece uma gestão mais eficiente. No entanto, as autoras alertam que esses argumentos tendem a dissociar a governança participativa do processo político, como se essa forma de gestão fosse capaz de "produzir 'naturalmente' decisões mais justas ou mais eficientes, e como se estas, por sua vez, gerassem automaticamente o apoio político necessário para a sua aplicação.” (Abers \& Keck, 2004, p. 56). 
Sem dúvida, o marco da descentralização trazido pela Lei das Águas é a criação dos Comitês de Bacias Hidrográficas. No entanto, apesar de a Política Nacional de Recursos Hídricos carregar, em si, o ideal de uma gestão de recursos integrada, colegiada e descentralizada, abrindo espaços de discussão, de decisão para a sociedade civil, o poder público e os usuários, o que caracteriza a formação dos Comitês de Bacias Hidrográficas, mais de quinze anos depois da promulgação da Lei das Águas, é a existência de diversos problemas no funcionamento de tais comitês.

$\mathrm{Na}$ visão de Abers \& Jorge (2005), um dos grandes problemas da descentralização na política nacional de recursos hídricos está na falta de incentivos para a cobrança pelo uso da água. Autonomia para definir preços e prioridades de investimentos com os recursos arrecadados seria a principal fonte de força política para os Comitês.

Em concordância, Cardoso (2003) traz várias críticas com relação à autonomia financeiro-administrativa da descentralização tida como vantagem e que, no caso dos comitês, essa independência ainda está longe de ser concretizada, uma vez que esta se exprime em poder de decisão sobre a gestão da bacia, o que significa aplicar recursos, os quais ainda são muito escassos. Dessa forma, pode-se dizer que seria incerto afirmar que, mesmo após quase duas décadas de reforma do Estado, se encontre no país um processo efetivo de descentralização das estruturas administrativas e das funções do Estado, pelo menos no que se refere à gestão de recursos hídricos.

Nesse mesmo sentido, Arretche (1996) já afirmava que o que existe é barganha em torno da descentralização fiscal, processo este que tem como um de seus desdobramentos a descentralização da despesa pública e o fortalecimento institucional dos níveis estadual e municipal, o que, na reflexão de Abers \& Jorge (2005), fazem com que, de um lado, o governo central ceda poder, e que, do outro lado, o poder local aceite as novas responsabilidades. Essas autoras afirmam, ainda, que a descentralização é um processo que ocorre de cima para baixo quando o governo federal repassa poderes para os municípios. Entretanto, na gestão de recursos hídricos o processo de descentralização ocorre de maneira diferente, uma que vez que a criação de organismos de bacia é feita, ao mesmo tempo, tanto no nível federal, quanto nos estaduais. Outro ponto levantado pelas autoras é que não ocorre a transferência de poder para níveis locais, mas a criação de uma nova instância chamada de bacia hidrográfica e, por último, destacam o fato de que nem todas as legislações estaduais obrigam a criação dos comitês.

De acordo com Alovisi Júnior \& Berezuk (2012), a descentralização é um ponto importante na gestão das águas, mas encontra dificuldades para ser implementada devido a fatores como falta de participação popular e estrutura que permita a cobrança da água. Desta forma, apesar de a descentralização ser apontada como forma de autonomia para as entidades, especificamente no caso dos comitês, essa autonomia não existe, uma vez que ela passa pela independência financeira, que se reflete na tomada de decisão de aplicação dos recursos e demais decisões político-administrativas.

Com base nisso, é possível recuperar alguns dos elementos previstos na Lei das Águas que potencializam o processo de descentralização e participação na gestão das águas no Brasil, conforme observado no Quadro 01. 
Elizabet Nunes, et al. Descentralização na gestão das Águas: um Processo ainda em construÇão?

\section{Quadro 01 -Descentralização e participação a partir da Lei das Águas}

\begin{tabular}{|c|c|c|}
\hline $\begin{array}{l}\text { MECANISMOS } \\
\text { NA LEI }\end{array}$ & PODER PÚBLICO & PODER COMPARTILHADO \\
\hline $\begin{array}{l}\text { I - os Planos } \\
\text { de Recursos } \\
\text { Hídricos; }\end{array}$ & & $\begin{array}{l}\text { Conforme a Lei das Águas } \\
\text { em seu artigo } 8^{\circ} \text { "os Planos } \\
\text { de Recursos Hídricos serâo } \\
\text { elaborados por bacia } \\
\text { hidrográfica, por Estado e } \\
\text { para o País". Nesse caso, os } \\
\text { comitês de Bacias são os } \\
\text { responsáveis pela elaboração } \\
\text { desses planos de Recursos } \\
\text { Hídricos. Acontece que a } \\
\text { maioria desses comitês não } \\
\text { possui recursos para a } \\
\text { elaboraçăo desses planos, o } \\
\text { que requereria recursos do } \\
\text { Estado para elaboraçăo. } \\
\text { Pode-se observar que, a } \\
\text { depender de quais interesses } \\
\text { o Estado seja subserviente, } \\
\text { os recursos podem não ser } \\
\text { destinados e os planos não } \\
\text { ser elaborados, impedindo a } \\
\text { implementação da cobrança } \\
\text { do uso da água conforme } \\
\text { rege a Lei das Agguas. }\end{array}$ \\
\hline $\begin{array}{l}\text { III - a } \\
\text { outorga dos } \\
\text { direitos de } \\
\text { uso de } \\
\text { recursos } \\
\text { hídricos; }\end{array}$ & $\begin{array}{l}\text { Esse poder é } \\
\text { concedido ao } \\
\text { Estado, que é } \\
\text { responsável pela } \\
\text { implementação } \\
\text { da Política } \\
\text { Estadual dos } \\
\text { Recursos } \\
\text { Hidricos. No caso } \\
\text { da Bahia, essa } \\
\text { responsabilidade } \\
\text { é do INEMA. Art. } \\
\text { 14. A outorga } \\
\text { efetivar-se-á por } \\
\text { ato da autoridade } \\
\text { competente do } \\
\text { Poder Executivo } \\
\text { Federal, dos } \\
\text { Estados ou do } \\
\text { Distrito Federal. } \\
\text { O artigo } 29, \\
\text { inciso II, dessa } \\
\text { mesma lei, } \\
\text { ratifica esse } \\
\text { poder e ainda } \\
\text { indica como de } \\
\text { sua competência } \\
\text { a fiscalização: II } \\
\text { - outorgar os } \\
\text { direitos de uso de } \\
\text { recursos hídricos, } \\
\text { e regulamentar e } \\
\text { fiscalizar os usos, } \\
\text { na sua esfera de } \\
\text { competência. }\end{array}$ & 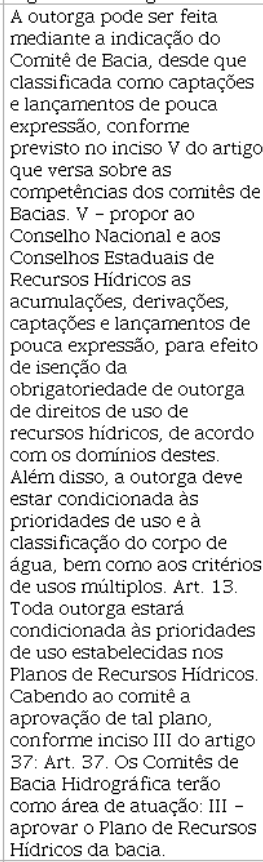 \\
\hline $\begin{array}{l}\text { IV - a } \\
\text { cobrança } \\
\text { pelo uso de } \\
\text { recursos } \\
\text { hídricos; }\end{array}$ & & $\begin{array}{l}\text { Caberá ao comitê de Bacias } \\
\text { Hidrográficas a instituição } \\
\text { dos mecanismos de } \\
\text { cobrança pelo uso da água. } \\
\text { Esse comitê é composto por } \\
\text { representes do poder } \\
\text { público, da sociedade civil e } \\
\text { dos usuários da água. A } \\
\text { gestão dos recursos } \\
\text { provenientes da instituição } \\
\text { da cobrança pelo uso da } \\
\text { água é feita na Agência das } \\
\text { Aguas, que estará } \\
\text { subordinada ao comitê. }\end{array}$ \\
\hline $\begin{array}{l}\text { Conselho } \\
\text { Nacional dos } \\
\text { Recursos } \\
\text { Hídricos }\end{array}$ & & $\begin{array}{l}\text { É composto por } \\
\text { representantes do poder } \\
\text { público, usuários e } \\
\text { representantes da sociedade } \\
\text { civil. Tem como competência, } \\
\text { dentre outras, arbitrar sobre } \\
\text { os conflitos do uso das } \\
\text { águas em última instância. }\end{array}$ \\
\hline $\begin{array}{l}\text { Comitê de } \\
\text { Bacias } \\
\text { Hidrográficas }\end{array}$ & & $\begin{array}{l}\text { É composto por } \\
\text { representantes do poder } \\
\text { público, usuários e } \\
\text { representantes da sociedade } \\
\text { civil. Tem como competência } \\
\text { arbitrar sobre os conflitos do } \\
\text { uso das águas em primeira } \\
\text { instância, outorgar o uso da } \\
\text { água de pouca expressão, } \\
\text { acompanhar a cobrança e } \\
\text { gestão dos recursos } \\
\text { provenientes através da } \\
\text { Agência das Aguas. }\end{array}$ \\
\hline
\end{tabular}


Fonte: Adaptado de Vitória, Fadul \& Cerqueira (2017, p.84).

Além disso, alguns outros pontos dificultam o processo de descentralização das águas no país, tais como: a predominância do poder do público no Conselho Nacional de Recursos Hídricos (CNRH), assegurando um protagonismo em relação aos demais participantes do sistema (Silva \& Pruski, 2000; Santos, Sampaio \& Rossi, 2006), como no caso da reversão da decisão desfavorável dada pelo comitê de bacia ao projeto de transposição do Rio São Francisco no CNRH (Spínola, Vitória \& Cerqueira, 2016); o duplo domínio das águas previsto em lei, que apregoa a regência das leis federais e, por conseguinte afeta a representação das subbacias estaduais, cujo poder de decisão é limitado à decisão dos comitês federais (Barth, 1996; Abers \& Jorge, 2005; Pereira \& Johnsson, 2005); e as dificuldades de integração com diversos setores para garantir os usos múltiplos previstos na Lei das Águas (Cerqueira, 2017).

Já na Bahia, alguns outros pontos reforçam ainda mais a dificuldade da descentralização das águas: a) a decisão do Conselho Estadual de Recursos Hídricos (CONERH) de aprovar os planos de recursos hídricos (Cerqueira, 2017), prerrogativa que é das Agências de Bacia (Silva e Pruski, 2000); a criação do Fundo Estadual de Recursos Hídricos do Estado da Bahia,(FERHBA) com a prerrogativa de gerenciar os recursos arrecadados com a cobrança pelo uso da água, mas que entra em conflito com a competência das Agências de Bacia conforme previsto na Lei das Águas (Cerqueira, 2017) e reforça o papel centralizador do estado da Bahia, já indicado por Santos, Sampaio \& Rossi (2006), e as dificuldades dos comitês de bacia na implementação dos instrumentos de gestão (Cerqueira, 2017).

\section{Procedimentos metodológicos}

Trata-se de um estudo exploratório e descritivo, que teve como foco principal o Comitê de bacia hidrográfica do Recôncavo Norte-Inhambupe, localizado no Estado da Bahia. Foi realizado através de pesquisa documental, analisando-se documentos do Ministério do Meio Ambiente, da Agência Nacional das Águas (ANA), da Secretaria de Meio Ambiente e Recursos Hídricos da Bahia e do comitê da bacia estudado.

A gestão de recursos hídricos através de comitês de bacias hidrográficas, legalmente requer a participação de três níveis de atores sociais que desempenham a função de representantes de seus respectivos interesses: representantes do poder público, representantes dos usuários (indústrias, agricultura irrigada, hidrelétrica, empresas de captação, tratamento e distribuição de água, etc) e os representantes da sociedade civil (organizações não-governamentais, movimentos sociais, igreja, etc.). A partir desse entendimento os procedimentos de coleta de dados escolhidos ocorreram mediante observação direta, entrevistas semiestruturadas realizadas com os membros da diretoria e aplicação de questionários com os demais membros do comitê, independente de qual parte interessada eles representassem. As observações não participantes foram realizadas durante as reuniões do comitê ocorridas nos meses de março, maio, setembro e novembro de 2013 e maio de 2014.

As entrevistas realizadas pelos autores procuraram investigar, de modo geral, como ocorreu a formação desse comitê, destacando os processos de descentralização e participação nessa formação. Sobre as motivações dos diretores para assumirem cargos de diretoria nesse comitê, se há renovação da diretoria, se diretores participam de outras atividades em alguma comunidade da bacia além do comitê, e se a renovação, tanto dos membros quanto dos membros da diretoria, poderia trazer benefícios ao comitê. Outras questóes trataram de como as atividades, deliberações e prestação de contas são informadas à sociedade, se há pessoas ou grupos que dificultam as atividades do comitê, quais os principais problemas enfrentados pelo comitê e questões sobre recursos financeiros do comitê.

De acordo com o Regimento Interno do Comitê, o colegiado pode ser composto por pessoas físicas e/ou jurídicas de direito público e privado, totalizando 45 membros que serão representados paritariamente entre os três segmentos. Desses 45 membros, três são eleitos os dirigentes (presidente, vice-presidente e secretário), 
sendo um representante de cada segmento. Os questionários foram dirigidos a todos os membros titulares dos três segmentos do comitê, sendo 10 questionários para o poder público, 14 para os usuários e 12 para a sociedade civil, totalizando 39 questionários.

Os questionários foram preenchidos pelos autores em contato direto com os respondentes. As perguntas feitas, de modo geral, procuraram verificar a percepção dos membros acerca do processo de formação do comitê, as razões que levaram à constituição desse comitê e se todos os municípios que compõem os diferentes trechos da bacia foram mobilizados para a sua formação. Outras questões focaram na capacitação dos membros para participar desse comitê, se o processo de escolha dos representantes na formação do Comitê ocorreu de maneira consensual e se os membros do Comitê representam bem as diferentes regióes geográficas da bacia. Outras questões envolveram os modelos descentralizado e participativo como sendo fatores potencializadores ou restritivos na implementação da gestão dos recursos hídricos por comitês de bacias.

Vale ressaltar que as reuniões dos comitês são públicas e abertas a todo cidadão ou instituição interessados nos assuntos relativos à água que serão tratados na pauta, sejam nas plenárias ou nas câmaras técnicas. Apesar de as reuniões serem públicas e abertas, a falta de divulgação das atividades desenvolvidas pelos comitês é algo notório. As entidades não possuem site próprio, o que dificulta a disseminação das informações, inclusive sobre as convocatórias das reunióes, que normalmente são enviadas por e-mail com o objetivo de atingir todos os membros.

\section{A descentralização da gestão de recursos hídricos no comitê de bacia hidrográfica do Recôncavo norte e Inhambupe}

A proposta da gestão integrada, participativa e descentralizada da água, realizada através dos comitês de bacias hidrográficas, se constitui em um processo complexo e de longo prazo. Considerando que esses comitês têm como principal finalidade realizar a gestão integrada dos recursos hídricos e que esse formato de gestão pressupõe a descentralização e a participação, a situação da bacia e todo o contexto que envolve as políticas de recursos hídricos podem influenciar bastante no papel e no desempenho do comitê.

A gestão descentralizada implica na capacidade de ação e sustentabilidade da entidade que passará a ser a responsável pela execução da gestão, exige grande capacidade de diálogo entre os atores públicos e privados envolvidos e também deve manter-se como coordenação conciliadora das atividades inerentes ao plano de bacia hidrográfica através dos comitês que fornecerão o espaço legal, institucional e político junto aos territórios aos quais pertencem as bacias hidrográficas.

Nesse contexto, um dos principais objetivos do Comitê de Bacia Hidrográfica do Recôncavo Norte e Inhambupe (CBHRNI) é o de promover uma gestão descentralizada e participativa da água, envolvendo o governo, a sociedade civil e os usuários. Criado em 2006, o Comitê de Bacia Hidrográfica do Recôncavo Norte teve a bacia de Inhambupe incorporada no ano de 2007, quando foram iniciadas as discussões acerca de assuntos administrativos e, posteriormente, pertinentes à elaboração do plano de bacia. De acordo com o regimento, o CBHRNI é composto por pessoas físicas e/ou jurídicas, de direito público e privado, tendo 45 membros, quinze para cada segmento, como forma de manter a equidade numérica para a participação e tomada de decisão tendo como base as diretrizes do sistema de gestão de recursos hídricos que vem sendo implementado no país.

A distribuição das vagas por segmento e por localidade é uma forma de favorecer a descentralização e a participação no comitê, e nesse comitê é possível notar que, de uma maneira geral, as vagas estão bem distribuídas entre os municípios que compõem a bacia. Contudo, faz-se importante observar que essa distribuição de vagas versus municípios não é homogênea quando relacionada às cadeiras ocupadas pelos segmentos. Existe uma concentração de vagas na região metropolitana de Salvador, que são ocupadas, em sua 
maioria, pelos usuários. Em contrapartida, as vagas das cidades mais distantes da capital são ocupadas pela sociedade civil organizada e pelo poder público. A centralização da realização das reuniões em Salvador, desde o seu processo de formação até o presente, pode ser um considerável fator de interferência para a presença dos membros desses segmentos nas reuniões plenárias.

Aparentemente, para alguns membros do comitê, não há um entendimento acerca dessa questão da descentralização da gestão das águas e do que ela efetivamente representa, nem conceitualmente, nem na prática do seu funcionamento. Apesar de $86 \%$ dos membros acreditarem que ela contribui para a melhoria e autonomia dos trabalhos da entidade, resta, ainda, $14 \%$ deles que consideram que a descentralização nem ajuda e nem atrapalha, o que leva a crer que ou esses membros não entendem o real significado dela, gostariam que houvesse uma maior intervenção do Estado ou, ainda, que não estão de acordo com a maneira como a descentralização ocorre dentro do comitê.

Quando perguntado sobre a formação do comitê, o presidente da entidade afirmou que esta havia acontecido de forma descentralizada e participativa, ressaltando que essa proposta de gestão é bastante propositiva. Porém, acrescenta que esse sistema ainda é muito lento e justifica a sua afirmação destacando que essa lentidão nas tomadas de decisão é uma característica do modelo participativo que, no caso do comitê, trabalha com três segmentos de interesses conflitantes, e a falta de capacitação dos seus membros. O vice-presidente concorda com essas afirmações, assegurando que a formação do comitê foi totalmente descentralizada e participativa, e realizada através de uma "mobilização boa, intensa e conflitiva".

Uma forma de avaliar a qualidade desse processo de descentralização é a atenção dada pelo governo do estado às decisões tomadas pelo comitê. Respeitar, acatar e dar seguimento a essas decisóes significa realmente que o governo estadual aceita esta divisão de poder com o comitê. Sobre esse posicionamento do governo com relação às decisões do comitê, ao serem perguntados, $36 \%$ dos membros não souberam informar qual era a postura adotada pelo governo, e 36\% afirmam que, às vezes, o governo ignorava as deliberaçóes do comitê e tomava suas próprias decisões.

Quando questionados sobre alguns aspectos estruturais do comitê, tais como a relação da entidade com as instituições do sistema nacional de recursos hídricos, a participação da ANA, o posicionamento do governo com relação às decisões do comitê e se a entidade recebe recursos de outras instituições além do governo do estado, a maioria dos entrevistados não soube responder. No que tange à efetiva participação da ANA na execução dos trabalhos do comitê, 39\% dos respondentes pertencentes ao órgão afirmaram desconhecer o assunto, 22\% disseram que a Agência nunca se envolveu e 17\% informaram que “às vezes” o órgão participava. No que se refere à frequência com que o comitê se relaciona com os órgãos do Sistema Nacional de Recursos Hídricos, obteve-se o seguinte resultado: $36 \%$ dos membros entrevistados afirmaram não saber a constância desse relacionamento, $23 \%$ responderam que "às vezes" e $18 \%$ disseram que "raramente" isso acontecia.

As razões desse desconhecimento podem ser várias. Pode-se supor que, para o poder público, a participação nos comitês ainda é incipiente e é mantida apenas para cumprimento da lei. Outra leitura possível é que as relações comitê versus governo ocorrem somente no nível da diretoria, e de forma não tão transparente para os demais, como foi justificado por alguns entrevistados. Outra possibilidade é a falta de engajamento e pertencimento dos membros do comitê, que pode comprometer a sua participação. Por fim e, talvez, a mais importante razão, é a de que a descentralização proposta pela Lei n ${ }^{\circ} 9.433 / 97$ efetivamente não funciona no comitê e o governo delibera de acordo os seus próprios interesses.

Com relação aos assuntos relativos à divulgação das atividades do comitê para a população, a diretoria afirmou que eles tentam fazer a divulgação dessas ações através das redes sociais, de correio eletrônico, de reuniões com as organizações, entre outros. Mencionaram também o papel do governo nesse processo de divulgação e, como o comitê não tem recursos e nem secretaria executiva para trabalhar na comunicação institucional, esta acaba sendo centralizada pelo estado, através da Secretaria Estadual de Meio Ambiente (SEMA) e do Instituto do Meio Ambiente e Recursos Hídricos (INEMA). 
Ainda dentro desse contexto, a opinião dos membros entrevistados sobre o cumprimento do papel do comitê é bastante dividida: $27 \%$ afirmaram que "quase sempre", $27 \%$ disseram que "raramente" e 23\% disseram que "sempre" esse é cumprido.

As opiniões também divergem no nível da diretoria como entre os demais membros. Para o presidente, o comitê tem trabalhado para isso, porém ainda não cumpre o seu papel, enquanto que o vice-presidente acredita na plenitude das atividades da entidade.

Um processo de descentralização, para ser efetivo, entre outros aspectos políticos a ela inerentes, pressupõe, também, não apenas autonomia administrativa como também financeira, para que possa ter êxito. Abers e Jorge (2005) já destacavam que um dos grandes problemas da descentralização na gestão das águas é a falta de recursos financeiros que são obtidos, neste caso, pela cobrança pelo uso da água. Esses recursos arrecadados pelos comitês, que devem gozar de autonomia para a definição de preços e prioridades de investimentos com os recursos arrecadados, seriam a sua principal força política. De fato, a falta de recursos financeiros foi apontada como o principal problema nesse comitê, pois o mesmo apenas recebe reembolso de despesas através do INEMA, órgão do governo do estado, não possui outra fonte de recurso e não tem como gerá-la por ainda não ter a agência de bacia implantada.

A cobrança pelo uso da água é a aplicação do princípio do usuário pagador e poluidor, por exemplo, as indústrias, companhias de saneamento e de geração hidrelétrica que pagam pelo montante de água que captam dos corpos d'água, que consomem no processo produtivo e que usam para diluição de efluentes. A capacidade de cobrança pelo uso da água através do comitê depende de ações do governo, tal como a definição do valor que será cobrado pelo serviço, que só é possível depois que o órgão estadual responsável implementar o sistema de outorga da água, que é a autorização de uso da água pelo poder público.

Procurando investigar, na perspectiva dos membros desse comitê, quais são os maiores fatores que dificultam o seu funcionamento, percebe-se que o primeiro é, efetivamente, a falta de recursos financeiros. O segundo maior problema enfrentado é a baixa mobilização da sociedade, que por sua vez desconhece o papel do comitê. Para eles, a sociedade também não se mobiliza de uma maneira geral com relação às questões voltadas à água, talvez por achar que esse papel seja do governo ou por acomodação, pela ausência de uma tradição de participação enraizada na sociedade brasileira e, também, pelo fato de se supor que o país tem abundância de recursos hídricos, prevalecendo a cultura de que a água do planeta é infinita.

A ausência da agência de bacia e, também, a não implantação da cobrança pelo uso da água, problemas que recaem na autonomia e na saúde financeira do comitê, ficaram juntas na terceira posição. O modelo de gestão descentralizada torna-se vulnerável a partir do momento em que esta entidade integra segmentos da sociedade, abre espaço para a tomada de decisões de forma participativa, mas não tem como executá-las por não ter recursos financeiros. Tem sempre que recorrer ao Estado para que este decida por financiar ou não as deliberações do comitê.

Os representantes do poder público, além de atentarem para a falta de recursos financeiros, apontam também como os principais problemas do comitê, o conhecimento técnico insuficiente dos membros, a baixa mobilização da sociedade civil e até mesmo a pouca participação dos representantes do poder público. Citando um exemplo da dependência financeira ao governo do estado, informaram que para a elaboração do plano da bacia foi aberta uma licitação, o serviço encomendado e pago pela Secretaria Estadual de Meio Ambiente (SEMA) e o comitê não interveio no processo de contratação do consórcio ganhador do certame formado por empresas do estado do Ceará.

No questionamento a respeito do nível de entendimento sobre a legislação de recursos hídricos, $64 \%$ avaliaram como "razoável", $23 \%$ como "ótimo" e $9 \%$ disseram que entendiam o mínimo. Analisando a pergunta de forma mais detalhada a partir dos segmentos, obteve-se os seguintes resultados: o segmento com melhor auto avaliação foi a sociedade civil, com 33\% dos respondentes afirmando que possuíam um ótimo conhecimento e $67 \%$ que o considerava como razoável. Dos três segmentos, o poder público foi o que menos 
soube avaliar seu nível de conhecimento, com $22 \%$ de respostas "não sei” e os usuários foram os que mais assumiram compreender o mínimo da citada legislação, com 14\% das respostas.

Para melhorar o conhecimento tanto do funcionamento do comitê quanto da legislação que rege os recursos hídricos, são oferecidos cursos de capacitação para os membros. A capacitação tem um papel importante visto que, dentre os principais problemas enfrentados, a falta de conhecimento técnico foi um dos mais citados, principalmente pelo segmento da sociedade civil.

Observando o conteúdo das atas e as reuniões, durante todo o ano de 2013, os assuntos mais discutidos dentro do CBHRNI sem dúvidas foram os que permearam a elaboração do plano de bacia. Todavia, de uma maneira geral, os respondentes informaram que os assuntos mais discutidos dentro do comitê são o conhecimento e avaliação da bacia e os problemas relacionados aos recursos hídricos (25\%), o funcionamento e organização interna do comitê (21\%) e a gestão de recursos hídricos (19\%).

Nota-se que os três assuntos mais debatidos são temas complexos e que exigem estrutura a nível administrativo e financeiro que o comitê não possui, como também da participação e do conhecimento principalmente técnico dos membros que se propuseram a discutir a temática da gestão das águas daquela bacia. Outro ponto que não pode ser ignorado é a necessidade de maior articulação política dos três segmentos, não só junto às suas entidades afins, como também com as comunidades da bacia.

\section{CONCLUSÃo}

Este trabalho identificou, analisou e discutiu os fatores propulsores e restritivos que têm influenciado a viabilidade da implementação do modelo de gestão de recursos hídricos, evidenciando a situação do comitê de bacia do Recôncavo Norte e Inhambupe, localizado no estado da Bahia, à luz da descentralização. O CBHRNI abarca, em sua composição, uma diversidade de atores e grupos de interesses que, através da Lei $\mathrm{n}^{\circ} 9.433 / 97$, buscam institucionalizar a descentralização política, institucional, financeira e gerencial de suas atividades.

Assim como na maioria das organizações, os comitês são considerados eficientes quando conseguem atingir a maioria dos seus objetivos, estabelecendo uma relação democrática, pluralista e participativa. No que se refere ao CBHRNI, o fato de a legislação aparentemente não ser totalmente cumprida, a não existência de um plano de bacia, a falta de autonomia financeira e, consequentemente administrativa e decisória, contribuem para um enfraquecimento da instituição.

As potencialidades e desafios da proposta de gestão descentralizada e participativa de recursos hídricos estão inseridas em um cenário que, por sua vez, envolve diversos elementos como o meio ambiente, o histórico das regiões das bacias, a relação das pessoas ou comunidades com os problemas referentes à água, a política em nível local e estadual e suas articulações dentro e fora das bacias, o engajamento e o comprometimento dos membros do comitê com o meio-ambiente e com a disponibilidade e uso da água, a interferência do poder público, a intervenção da sociedade civil, o nível de conhecimento técnico sobre recursos hídricos; a visibilidade do comitê dentro das bacias, o acesso à informação sobre a política de recursos hídricos, entre outros elementos.

A forma como são compostos os comitês, definidos por lei e estruturados em segmentos (poder público, usuários e sociedade civil), encerra ao mesmo tempo diversas potencialidades e também fragilidades no que se refere à representação. Por outro lado, essa segmentação tripartite e paritária do comitê contribui para que todos os grupos tenham representação numérica uniforme, cabendo a cada segmento saber escolher as instituições que irão representá-los melhor.

Apesar de a Lei no 9.433/97 ter trazido conceitos bastante aceitos, como integração, descentralização e participação, estes, devido à sua complexidade, vêm encontrando, de certa forma, diversas dificuldades de implementação. A implantação da descentralização na qual atribui a bacia hidrográfica o status de unidade de gestão e articulação territorial, ainda está aquém de ser totalmente concretizada, visto que o governo 
estadual ainda detém o poder institucional e financeiro, o que compromete o efetivo poder de decisão do comitê. Contudo, a descentralização também permite a utilização de instrumentos de gestão como a direção e o controle e que podem auxiliar esse processo para que muitas das dificuldades sejam vencidas e outros mecanismos possam ser aplicados.

A baixa rotatividade dos seus membros contribui positivamente para que o comitê conserve a maior parte de sua bagagem histórica, que serve como ponto de referência para pesquisa, avaliação e norteamento dos demais componentes nas futuras atividades a serem realizadas dentro da entidade.

Nesse aspecto, a perenidade dos membros da diretoria que apresentam um perfil técnico pode ser considerada como um fator potencializador, olhando pelo o viés da liderança que, aparentemente, tem se mostrado forte, articulada e até consolidada dentro do Comitê. Todavia, esse fato também demonstra a pouca vontade ou capacidade de participação e articulação dos membros dos três segmentos em provocar mudanças e trazer novos direcionamentos para a gestão dessa organização.

Há que se considerar, ainda, as dificuldades econômicas de alguns membros, principalmente os da sociedade civil, que precisam arcar com as suas próprias despesas, além de terem que se deslocar para as reuniões que acontecem na cidade de Salvador. Assim como ocorre na maioria dos comitês de bacias do Brasil, a falta de recursos financeiros é vista como o principal problema uma vez que afeta o funcionamento e a autonomia da entidade. A cobrança pelo uso da água é considerada um instrumento que proporcionaria a promoção do uso responsável da água pelos pagantes e, também, que geraria recursos para a manutenção das atividades e projetos no setor de recursos hídricos.

O comitê estudado tem buscado, dentro do possível, cumprir as determinações das leis de recursos hídricos no âmbito nacional e estadual, como também o seu regimento, no que diz respeito à estruturação, promovendo a formação de câmaras técnicas e grupos de trabalho com o objetivo de gerar discussões e encaminhamentos. Contudo, a institucionalização do comitê ainda é incipiente. De fato, a gestão descentralizada neste comitê é ainda um processo em construção. Para que o comitê possa crescer em sua trajetória, não se pode permitir que antigos entraves ganhem força, como os interesses políticos e eleitorais e as desigualdades de uma maneira geral, prejudicando o enraizamento da gestão descentralizada e compartilhada dos recursos hídricos.

\section{REFERÊNCIAS}

ABERS, Rebecca N., KECK, Margaret E. (2004). Comitês de Bacia no Brasil, uma abordagem política no estudo da participação social. R.B. Estudos Urbanos e Regionais, V.6, n.1.

ABERS, Rebecca N.; JORGE, Karina D. (2005). Descentralização da gestão da água: Por que os comitês de bacia estão sendo criados? Ambiente \& Sociedade - Vol. VIII No. 2,1-26.

ABRUCIO, F. L. (2002). Descentralização e coordenação federativa no Brasil: lições dos anos FHC. In: ABRUCIO, Fernando Luiz; LOUREIRO, Maria Rita (Org.). O Estado numa era de reformas: os anos FHC. (parte 2, 143-216). Brasília: MP, SEGES.

ABRÚCIO, Fernando L.(2006). Para além da descentralização: os desafios da coordenação federativa no Brasil. Democracia, descentralização e desenvolvimento: Brasil e Espanha. Rio de janeiro: Editora FGV, 77-125.

ALOVISI JÚNIOR, Valmor; BEREZUK, Geraldo A. (2012). Análise comparativa de gestão de recursos hídricos em Portugal e no Brasil. Revista Portuguesa de Recursos Hídricos. Vol. 33, N. 1.

ARRETCHE, M. (1996). Mitos da descentralização: mais democracia e eficiência nas políticas públicas?Revista Brasileira de Ciências Sociais. São Paulo, 11(31).

BARRAQUÉ, Bernard., FORMIGA JOHNSSON, Rosa M.; NOGUEIRA, Ana. L.de P. B. (2008). The Development of Water Services and their Interactions with Water Resources in European and Brazilian Cities, Hydrologyand Earth System Sciences, 12, 1153-1164. 
BARTH, F. T. (1996).A recente experiência brasileira de gerenciamento de recursos hídricos, Cadernos FUNDAP, n. 20.

BORSOI, Zilda M. F.; TORRES, Solange D. A. (1997). A política de recursos hídricos no Brasil. Rio de Janeiro: Revista BNDES 4(8):143-166.

BRASIL. (1967). Decreto-Lei n 200, de 25 de fevereiro de 1967. Dispõe sobre a organização da Administração Federal, estabelece diretrizes para a Reforma Administrativa e dá outras providências. Senado Federal. Disponível em https://www12.senado.leg.br/orcamento/documentos/legislacao/decreto-lei-200/view

BRASIL. (1998). Constituição da República Federativa do Brasil. Diário Oficial da União, Brasília, 5 out. 1988.

BRASIL. Lei no 9.433 de 8 de janeiro de 1997. Política Nacional de Recursos Hídricos. Brasília: Secretaria dos Recursos Hídricos, Ministério do Meio Ambiente, dos Recursos Hídricos e da Amazônia Legal.

CERQUEIRA, Lucas Santos. (2017). Governança das águas na Bahia: uma análise da política estadual de recursos hídricos à luz da descentralização, da participação social e da cobrança. 2017. 290p. Tese (Desenvolvimento Regional e Urbano) - UNIFACS Universidade Salvador, Salvador.

DAGNINO, Evelina. (2004). Sociedade civil, participação e cidadania: de que estamos falando? In: MATO, Daniel (Coord.). Políticas de ciudadania y sociedad civil em tiempos de globalizacion. Caracas: Faces, Universidad Central de Venezuela.

DI PIETRO, Maria Sylvia Zanella (2010). Direito Administrativo. - 23. ed. - São Paulo: Atlas.

FADUL, E. M. C. ; VITORIA, F. T. ; CERQUEIRA, L. S. (2017).A governança participativa na gestão de recursos hídricos no brasil: uma análise da realidade do estado da Bahia. SINERGIA, V. 21, n.1.

FREITAS, M. de; RANGEL, D.; DUTRA, L. (2001).Gestão dos recursos hídricos no Brasil: a experiência da Agência Nacional das Águas. In: III Encuentro de las Aguas, Santiago de Chile, 24-26.

GUIMARÃES, Maria do Carmo Lessa. (2014). O debate sobre a descentralização de políticas públicas: um balanço bibliográfico. Organizações \& Sociedade, v. 9, n. 23.

MACHADO, Carlos J. S. (2003). Recursos hídricos e cidadania no Brasil: limites, alternativas e desafios. In: Ambiente $\&$ Sociedade. Vol. VI, n 2, 122-136.

MELLO, Celso Antônio Bandeira de. (2000). Curso de Direito Administrativo. - 12a . ed. - São Paulo: Malheiros.

MÉSZÁROS, Instván. (2002). Para além do capital - rumo a uma teoria da transição. São Paulo: Boitempo Editorial.

PEREIRA, Dilma. S. P.; FORMIGA-JOHNSSON, Rosa. M. (2005). Descentralização da gestão dos recursos hídricos em bacias nacionais no Brasil. Revista de Gestão da Água na América Latina.Vol.2 - n.1. Santiago: GWP/South America.

PEREIRA, Maria do C. N. (2008). Composição do Comitê da bacia Hidrográfica do rio: análise da origem geográfica e do setor econômico apresentado por seus membros como fatores intervenientes na gestão participativa de recursos hídricos. Universidade de Brasília. Brasília - Distrito Federal.

PLANO NACIONAL DE RECURSOS HÍDRICOS (2006). Panorama e estado dos recursos hídricos do Brasil: Volume 1 - Ministério do Meio Ambiente, Secretaria de Recursos Hídricos - Brasília: MMA.

RIO, G. A. P. do; MOURA, V. P.; SALES, A.V.S. (2004). Gestão de recursos hídricos: aspectos metodológicos. In: ENCONTRO DA ASSOCIAÇÃO NACIONAL DE PÓS GRADUAÇÃO E PESQUISA EM AMBIENTE E SOCIEDADE ANPPAS, 2., 2004, São Paulo. Anais.

SANTOS, M. E. P. (2002). As Águas como direito e como commodity - uma contradição em termos? RDE - Revista de Desenvolvimento Econômico, Salvador, v. 4, n. 6, 60-70.

SANTOS, M.E.P.dos; SAMPAIO, R.M; ROSSI, R. A. (2006). Análise Comparativa do Significado da Participação nos Comitês das Bacias dos Rios Paraguaçu e São Francisco. Núcleo ÁGUAS/NEPOL-CIAGS/EA-UFBA. In: ENCONTRO DA ANPPAS, 3., Brasília, 2006. Anais.

SILVA, D. D.; PRUSKI, F. F. (Ed.). (2000) Gestão de Recursos Hídricos: aspectos legais, econômicos, administrativos e sociais. Brasília, DF: Secretaria de Recursos Hídricos; Viçosa, MG: Universidade Federal de Viçosa; Porto Alegre: Associação Brasileira de recursos Hídricos. 
Elizabet Nunes, et aL. Descentralização na gestão das Águas: um PRocesso ainda em CONSTRUÇão?

SOUZA, Manoel T.A. de. (1997). Argumentos em Torno de um "Velho" Tema: A Descentralização. Dados, Rio de Janeiro, v.40, n. 3 .

SPÍNOLA, Carolina; VITORIA, Fabrício; CERQUEIRA, Lucas.(2016): A Lei das Águas e o São Francisco: Os Limites da Gestão descentralizada dos Recursos Hídricos No Brasil. Revista de Desenvolvimento Econômico RDE - Ano XVIII, vol. 1, n. ${ }^{\circ} 33, .70$ - 90.

CC BY-NC-ND 